As this infrequent complication of proximal gastric vagotomy causes morbidity and mortality methods for its prevention should be considered. Plication of the lesser curve to bury and reperitonealize the bared area may be effective.

We thank Mr. K. W. Reynolds for permission to study this patient, who was under his care.

${ }^{1}$ Johnson, D., Gut, 1974, 15, 748.

2 Newcombe, J. F., British Medical fournal, 1973, 1, 610.

3 Kalaja, E., et al., Surgery, 1975, 77, 140.

${ }^{4}$ Kennedy, T., et al., British Medical fournal, 1975, 2, 301.

${ }^{5}$ Wyllie, J. H., British Medical fournal, 1974, $2,561$.

Charing Cross Hospital, London W6 8RF

R. W. HOILE, M.B., F.R.C.s., Surgical Registrar

J. C. D. TURNER, M.B., B.S., House Surgeon

\section{Equinus Deformity and Haemangioma of Calf Muscle}

The cause of equinus associated with calf pain in children can be difficult to elucidate. We report two children in whom the diagnosis was finally established, in one by arteriography and in the other by exploration. In the second child the symptoms were thought to be hysterical. Both children were found to have an haemangioma in a calf muscle.

\section{Case Reports}

Case 1.-A 9-year-old girl presented with a year's history of pain in the right shin. This had begun three weeks after a spiral fracture of the opposite tibia had been treated successfully by immobilization. Examination showed a fit girl who walked with a limp. Her right calf was wasted (by $2 \mathrm{~cm}$ ) and there was a slight swelling just behind the subcutaneous border of the middle third of the tibia. Firm pressure produced severe pain at this site. There was a fixed equinus deformity which did not correct when the knee was flexed. She showed no neurological abnormalities. Plain radiographs showed no abnormality and her erythrocyte sedimentation rate was $4 \mathrm{~mm}$ in one hour. In view of the marked local tenderness a diagnosis of glomus tumour was entertained and an arteriogram performed which showed a small vascular mass (see fig.). At operation a swelling was palpable within the substance of the lower muscle bulk of the soleus. This was removed with a clear margin of normal muscle. The child recovered uneventfully, full dorsiflexion of the ankle returned, and she could walk normally. Histological examination showed the lesion to be a cavernous haemangioma infiltrating muscle.

Case 2.-A 9-year-old girl presented with pain behind her right knee and an 18-month history of difficulty in walking. Several months previously at

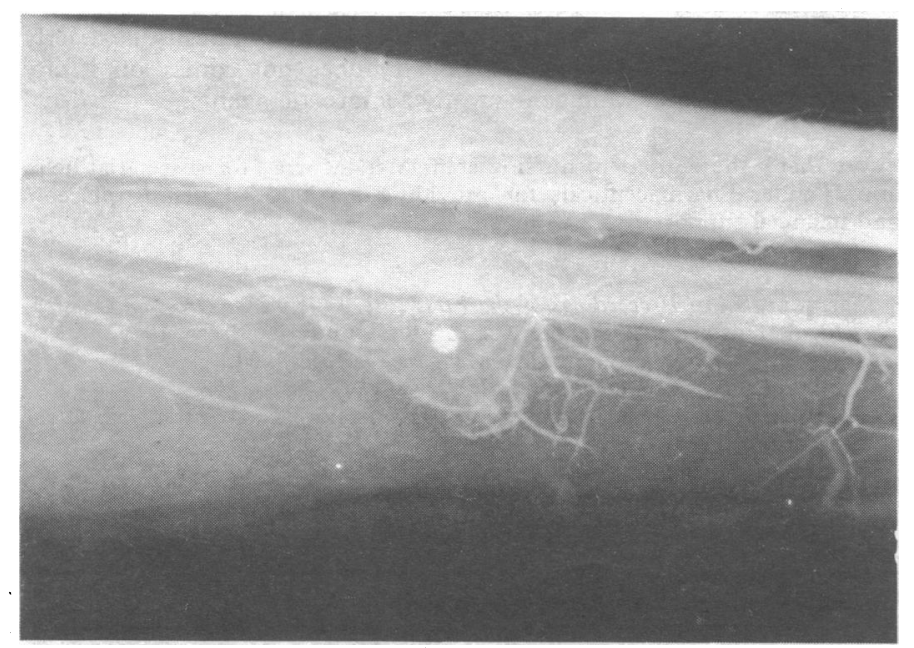

Femoral arteriogram showing vascular mass in middle of calf in direct relation to shot marker at site of tenderness another hospital popliteal cyst had been diagnosed, but surgical exploration found nothing. Examination showed wasting of the right calf and an equinus deformity which was largely corrected by knee flexion. She was locally tender deep to the operation scar in the popliteal fossa. Neurological examination, including lumbar puncture and electromyography, and plain radiographs showed no abnormalities. Hysteria was then suspected until the equinus was found to persist under general anaesthesia. The popliteal fossa was re-explored, and a small dark vascular tumour was found deep in the medial head of the gastrocnemius. This was removed. After the operation the equinus deformity was corrected immediately and the child recovered uneventfully. Histological examination showed the tumour to be an hamartomatous haemangioma.

\section{Discussion}

Equinus associated with calf pain is unusual and the possibility of an intramuscular haemangioma should always be considered. Discrete tenderness and an equinus which persists under general anaesthesia are important signs, and arteriography is a valuable investigation. Exploration and excision may be both curative and diagnostic.

We thank Mr. G. Lloyd-Roberts and Mr. Geoffrey Walker for permission to report their cases.

Hospital for Sick Children, Great Ormond Street, London W.C.1

R. C. CLARKE, F.R.c.s., Orthopaedic Specialist. (Now at Royal Naval Hospital, Plymouth, Devon)

Queen Mary's Hospital for Children, Carshalton, Surrey

R. J. J. WENGER, F.R.c.s., Orthopaedic Registrar. (Now at St. George's Hospital, London)

\section{Inhibitory Effect of Oral Doxantrazole on Asthma Induced by Allergen Inhalation}

Sodium cromoglycate (Intal) has proved valuable in the prophylaxis of asthma, but must be given by inhalation because of poor intestinal absorption. Some patients find it difficult to use the Spinhaler so that an orally active compound would be advantageous. A new compound 3-(5-tetrazolyl)thioxanthone 10,10-dioxide (proposed approved name doxantrazole) has this potential. The compound is active in several systems in a similar way to cromoglycate; for example, it suppresses the passive cutaneous anaphylaxis reaction and allergic bronchoconstriction in rats in vitro and inhibits the release of histamine from passively sensitized chopped human lung challenged with an extract of grass pollen. ${ }^{1}$

\section{Patients, Methods, and Results}

The effect of the drug was tested on eight asthmatic patients allergic to house dust mite (Dermatophagoides pteronyssinus); all were positive on skin tests. Inhalation challenge tests had indicated the dose of allergen that would produce a $20-30 \%$ fall in forced expiratory volume in one second $\left(F E V_{1}\right)$. Using the same challenge technique ${ }^{2}$ challenges were performed at least one week apart. The patients were pretreated with either doxantrazole (as $200 \mathrm{mg}$ of the sodium salt in a freshly made up solution in $100 \mathrm{ml}$ of water) or placebo ( $200 \mathrm{mg}$ of lactose) one hour before the challenge. The two treatments were given double-blind and in random order. Vital capacity (VC) FEV , peak expiratory flow rate (PEFR), pulse rate, and blood pressure were measured on arrival at the laboratory and an hour later when the drug was given. These were repeated immediately before the challenge, and further measurements were made $5,15,30$, and 60 minutes after challenge and then every hour for four hours. The patients left the laboratory with instructions to record their peak flow rates every hour. Cromoglycate was discontinued for 24 hours before the challenge procedure and all other antiasthma drugs for 12 hours.

The table shows mean falls in VC, FEV , $_{\text {, }}$ and PEFR after inhalation challenge after doxantrazole and placebo. There was a significant difference between drug and placebo in the immediate reactions of $F_{1}$ and PEFR. Six patients showed delayed reactions which started five hours or more after inhalation challenge. There was no difference in the maximum reduction of PEFR during this period but this might have resulted from the greater use 
Mean Reduction in VC, FEV , and PEFR ( \pm S.D.) Immediately after Inhalation Challenge after Pretreatment with Placebo and Active Drug

\begin{tabular}{|c|c|c|c|}
\hline & Placebo & Doxantrazole & Difference* \\
\hline VC (1) & $0.76 \pm 0.52$ & $0.48 \pm 0.24$ & $0.28 \pm 0.51$ (N.S) \\
\hline $\mathrm{FEV}_{1}(\mathrm{l})$ & $0.78 \pm 0.65$ & $0.45 \pm 0.42$ & $0.33 \pm 0.35$ \\
\hline PEFR $(1 / \min ) \ldots$ & $111 \pm 72 \cdot 2$ & $63 \pm 58 \cdot 6$ & $\begin{array}{l}(48 \pm 23.1 \\
\mathrm{P}<0.001)\end{array}$ \\
\hline
\end{tabular}

*P values were assessed with student's $t$ test. N.S. $=$ Not significant

of bronchodilators after placebo in some patients. The initial mean values of VC, FEV 1 , and PEFR immediately before challenge after either pretreatment were not significantly different. The mean percentage falls in $\mathrm{FEV}_{1}$ and PEFR in the placebo-treated group were 29.4 and $27.4 \%$ respectively, indicating that a significant response to challenge had occurred.

\section{Discussion}

These results in a few patients suggest that doxantrazole may be valuable in the treatment of asthma. A similar protection against asthma induced by allergen challenge has been reported for the orally administered compound $\mathrm{AH} 7725,{ }^{3}$ but the value of disodium cromoglycate was proved by long-term trials ${ }^{4}$ rather than such singledose studies. Further clinical trials are obviously needed to establish the long term efficacy of doxantrazole and determine which patients are likely to respond. Nevertheless, these preliminary findings are encouraging. Apart from difficulties with the Spinhaler an important disadvantage of cromoglycate is that it may cease to be effective in patients with severe airways obstruction because it is not effectively inhaled into their lungs. ${ }^{5}$ An orally active drug should be effective however severe the degree of airways obstruction.

1 Batchelor, J. F., et al., Lancet, 1975, 1, 1169.

${ }^{2}$ Haydu, S. P., Empey, D. W., and Hughes, D. T. D., Clinical Allergy, $1974,4,449$.

${ }^{3}$ Asscm, E. S. K., Evans, J. A., and McAllen, M. K., British Medical Fournal, 1974, 2, 93.

4 Howell, J. B. L., and Altounyan, R. F. C., Lancet, 1967, 3, 539.

${ }^{5}$ Benson, M. K., et al., Clinical Allergy, 1973, 3, 389.

Pulmonary Research Unit, Department of Chest Medicine, The London Hospital, London E.1

S. P. HAYDU, M.B., M.R.C.P., Research Fellow (Present address: East Birmingham Hospital, Birmingham 9)

JANE L. BRADLEY, M.B., M.R.C.P., Research Fellow (Present address St. Thomas's Hospital, London S.W.1)

D. T. D. HUGHES, B.M., F.R.C.P., Consultant Physician

\section{Double-blind Evaluation of Mazindol in Refractory Obesity}

Mazindol (Teronac) is an isoindole compound with anorectic properties. It has been claimed that its pharmacological action is fundamentally different from that of the sympathomimetic amines, that it produces sustained weight loss, and that it helps to re-establish good eating habits. We undertook to evaluate its efficacy in patients with refractory obesity.

\section{Patients, Methods, and Results}

Fifty women, more than $20 \%$ in excess of their ideal weight, with refractory obesity were randomly divided into two groups. One group was instructed to take mazindol $2 \mathrm{mg} 60$ minutes before the midday meal and the other group to take an identical placebo tablet. All were given further dietary advice based on the principle of carbohydrate restriction. They had to attend every fortnight during the 12-week treatment period and again two weeks later. At each visit they were weighed, the blood pressure was recorded, and they were asked about side effects. The tablets were dispensed from the clinic and any patient failing to attend on two consecutive occasions was withdrawn.
Two patients receiving mazindol defaulted and six, four of them on mazindol, were withdrawn because of side effects. The mean age, ideal weight, and percentage in excess of ideal weight of the 23 patients receiving placebo and the 19 receiving mazindol who completed the study were comparable. The mean weight change in the placebo group during the treatment period was $-0.3 \mathrm{~kg}$ (range +3.2 to $-4.6 \mathrm{~kg}$ ), 10 patients gaining and 13 losing weight. In the mazindol group the mean weight change was $-1.4 \mathrm{~kg}$ (range +2.7 to $-8.6 \mathrm{~kg}) ; 11$ lost weight and only three lost more than $5 \mathrm{~kg}$. The maximum weight loss on mazindol occurred at six weeks (see fig.). Only five patients with the greatest total weight losses $(8 \cdot 6,6 \cdot 8,5 \cdot 9,4 \cdot 5$, and $3 \cdot 6 \mathrm{~kg}$ respectively) lost any weight during the second six weeks. The 13 patients on mazindol who reattended two weeks after treatment stopped had regained a mean oi $+1.0 \mathrm{~kg}$ compared with $+0.1 \mathrm{~kg}$ in the 16 women who had received placebo. Only four patients taking mazindol and one receiving placebo had suppressed appetites during the treatment period. There was no material change in blood pressure, and, generally, the side effects on mazindol were similar to those previously reported: five patients complained of excessive sweating and one had to be withdrawn.

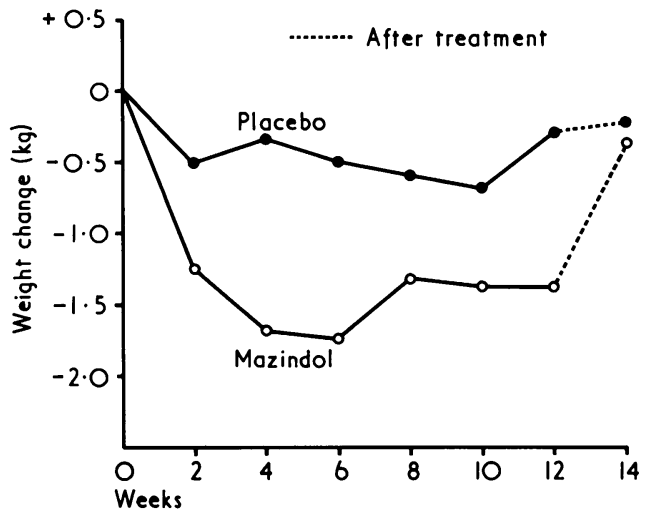

Weight change in active and placebo groups.

\section{Discussion}

Though clinically unrelated to amphetamine mazindol is a central nervous system stimulant and its neuropharmacological action is comparable to that of amphetamine. ${ }^{1}$ When given double-blind to amphetamine addicts it produces a subjective sensation similar to but less pronounced than that of amphetamine. Mazindol should be treated as a potential drug of abuse.

Studies have suggested that mazindol is an effective anorectic agent in the short term, causing weight loss comparable or superior to that achieved by phenmetrazine, dexamphetamine, and fenfluramine. ${ }^{2} 4$ We found, however, that the mean weight loss was disappointing, and only lasted about six weeks, and, when contrasted with findings in similar studies in comparable patients, was less than that achieved with chlorphentermine, phenmetrazine, phentermine, and fenfluramine. ${ }^{5}$ This is consistent with others' observations, ${ }^{2}{ }^{4}$ and reports of more prolonged effects may merely reflect differences in patient selection. ${ }^{3}$ The rapid weight regain in our patients would refute the claim that mazindol helps to re-establish good eating habits. There is no firm evidence to suggest that anorectics will modify subsequent eating habits, and their role in the management of obesity is strictly limited. Mazindol's biochemical novelty does not confer on it any important clinical advantage over other anorectic agents.

We thank the outpatient nursing staff, Mrs. Murray for secretarial help, and Wander Pharmaceuticals for providing mazindol, matching placebo, and financial support.

${ }^{1}$ Garratini, S., in Proceedings of the First International Congress on Obesity, ed. A. Howard. Cambridge, Cambridge University Press, 1975.

2 Conte, A., Obesity and Bariatric Medicine, 1973, 2, 104.

3 Kornhaber, A., Annals of Internal Medicine, 1973, 76, 162

4 Goldrick, R. B., Nestel, P. J., and Havenstein, N., Medical fournal of Australia, 1974, 1, 882.

5 Munro, J. F., British fournal of Hospital Medicine, 1973, 10, 8.

Eastern General Hospital, Edinburgh EH6 7LN

R. G. SMITH, M.B., M.R.C.P., Senior Registrar

J. A. INNES, M.B., M.R.C.P., Registrar

J. F. MUNRO, M.B., F.R.C.P., Consultant Physician 